\title{
Características da fermentação e estabilidade aeróbia de silagens de milho inoculadas com Bacillus subtilis
}

\author{
Fermentation characteristics and aerobic stability of corn silages inoculated with \\ "Bacillus subtilis"
}

\author{
BASSO, Fernanda Carvalho ${ }^{1 *}$; LARA, Erika Christina ${ }^{1}$; ASSIS, Flávia Borges de ${ }^{1}$; \\ RABELO, Carlos Henrique Silveira ${ }^{1}$; MORELLI, Marcela ${ }^{1}$; REIS, Ricardo Andrade ${ }^{1}$
}

${ }^{1}$ Universidade Estadual Paulista, Faculdade de Ciências Agrárias e Veterinárias, Jaboticabal, São Paulo, Brasil.
*Endereço para correspondência: fcarvalhobasso@yahoo.com.br

RESUMO

Objetivou-se avaliar os efeitos da inoculação de Bacillus subtilis sobre as características e perdas ocorridas na fermentação, no desenvolvimento de leveduras e fungos filamentosos e na estabilidade aeróbia de silagens de milho. Estudou-se o milho híbrido 2B655, no qual avaliaram-se os seguintes tratamentos: silagem sem inoculação de $B$. subtilis e silagens inoculadas com $B$. subtilis nas concentrações de $5 \times 10^{4} ; 1 \times 10^{5}$ e $5 \times 10^{5} \mathrm{UFC} / \mathrm{g}$ de forragem. $\mathrm{O}$ delineamento experimental utilizado foi o inteiramente casualizado, em esquema de parcelas subdivididas, em que as silagens constituíram as parcelas e os tempos de exposição aeróbia as subparcelas, com quatro repetições. Os dados obtidos foram submetidos à análise de variância por meio do software SISVAR ${ }^{\circledR}$, bem como aplicou-se a análise de regressão a $5 \%$ de significância. A aplicação de $B$. subtilis não alterou as características químicas e as perdas no processo de fermentação da silagem de milho. A contagem de leveduras na abertura dos silos foi reduzida, assim como a população de fungos filamentosos diminuiu durante a exposição aeróbia, o que implicou em menores valores de $\mathrm{pH}$ e resultou em maior estabilidade aeróbia, devido à utilização da maior dose de B. subtilis. A inoculação de Bacillus subtilis na concentração de $5 \times 10^{5} \mathrm{UFC} / g$ de forragem controla o crescimento dos microorganismos deterioradores e melhora a estabilidade aeróbia da silagem de milho, a manter os valores de $\mathrm{pH}$ mais estáveis na fase de pósabertura dos silos.

Palavras-chave: deterioração, fungos filamentosos, leveduras, silagem de milho, temperatura.

\section{SUMMARY}

The aim with this present study to evaluate the effects of inoculation of Bacillus subtilis on the fermentation characteristics and losses, on the development of yeasts and molds and aerobic stability of corn silages. The corn studied was the hybrid 2B655 with the next treatments: untreated silage (control) and corn silages inoculated with $B$. subtilis in the concentrations of $5 \times 10^{4} ; 1 \times 10^{5}$ and $5 \times 10^{5} \mathrm{cfu} / \mathrm{g}$ of fresh forage. The experimental design was completely randomized in a split-plot, in which the silage was the main plots and the exposure times aerobic sub-plots with four replications. The data were subjected to analysis of variance using SISVAR ® software, applying regression analysis to $5 \%$ significance level. The inoculation of $B$. subtilis did not alter the fermentation characteristics and losses. The yeast count was reduced at the time of opening of the silo, as the molds population decreased during the air exposure, which resulted in lower $\mathrm{pH}$ values. These facts resulted in increase aerobic stability when the highest dose of $B$. subtilis was applied. The inoculation of $B$. subtilis in the concentration of $5 \times 10^{5} \mathrm{cfu} / \mathrm{g}$ forage controls the growth of yeasts and improves the aerobic stability in corn silage, while maintaining the $\mathrm{pH}$ more stable in the post-opening of the silos.

Keywords: corn silage, deterioration, molds, temperature, yeasts. 


\section{INTRODUÇÃOO}

Países situados entre os trópicos apresentam redução na produção de forragens durante o período da seca. Dessa forma, os índices mensuráveis na produção de ruminantes, mantidos em regime de pastejo, são afetados, sobremaneira, pela baixa disponibilidade de alimento em quantidade e qualidade, nesse período, o que remete à utilização de forragens conservadas. Entre as culturas mais utilizadas para essa finalidade, encontra-se o milho (Zea mays), pois apresenta características desejáveis na produção de silagem, como alta produtividade, alto valor nutritivo e adequado processo de fermentação (ZEOULA et al., 2003).

A alta concentração de nutrientes e carboidratos solúveis residuais do processo fermentativo em silagens de milho pode levá-las a apresentar baixa estabilidade após a abertura dos silos, pois micro-organismos oportunistas e indesejáveis utilizam os substratos para se desenvolverem (TAYLOR et al., 2002). Segundo Woolford (1990), a deterioração da silagem, quando exposta ao ar, é inevitável e pode resultar em perda substancial de matéria seca. Esses eventos ocorrem, principalmente, em silagens resultantes de fermentação desejável, cuja marca é a elevada concentração de lactato (MUCK, 2010), o que sugere a busca por novas cepas de micro-organismos que promovam aumento da estabilidade aeróbia das silagens.

Nesse sentido, espécies e cepas do gênero Bacillus produzem substâncias com ação antimicrobiana, inclusive antibióticos, o que possibilita a utilização destas no controle biológico de fitopatógenos (LANNA FILHO et al., 2010). De acordo com Todovora \& Kozhuharova (2009), a espécie Bacillus subtilis é uma das mais importantes produtoras de metabólitos com atividade antifúngica e antibacteriana do gênero Bacillus.

Especificamente no caso de silagens, não há muitos trabalhos que estudam essa espécie, contudo, Phillip \& Fellner (1992) avaliaram a aplicação de $B$. subtilis em silagens de milho $\mathrm{e}$ verificaram efeito positivo sobre a estabilidade aeróbia desses volumosos. Dessa maneira, a utilização do $B$. subtilis torna-se mais uma alternativa no controle da instabilidade aeróbia de silagens.

Portanto, objetivou-se avaliar os efeitos da inoculação de B. subtilis sobre as características e perdas fermentativas, bem como o desenvolvimento de leveduras e fungos filamentosos e a estabilidade aeróbia em silagens de milho.

\section{MATERIAL E MÉTODOS}

O experimento foi conduzido no setor de Forragicultura do Departamento de Zootecnia da Faculdade de Ciências Agrárias e Veterinárias da Universidade Estadual Paulista (FCAV/UNESP), campus de Jaboticabal - SP. Para a produção das silagens utilizou-se $\mathrm{O}$ milho híbrido 2B655 (Dow Agroceres), colhido manualmente a $10 \mathrm{~cm}$ da superfície do solo, quando os grãos apresentavam-se no estádio farináceo. As plantas foram cortadas em picadora estacionária, com o tamanho de partículas de $10 \mathrm{~mm}$.

Antes do enchimento dos silos experimentais, o inoculante comercial (Biotop $^{\circledR}$ ), que continha Bacillus subtilis, foi pesado em balança analítica de precisão para obter as diferentes doses testadas com base na concentração inicial do produto $\left(1 \times 10^{9}\right.$ unidades formadoras de colônias - 
UFC/g de produto). Posteriormente, foi diluído em água destilada e pulverizado sobre a massa de forragem.

Os tratamentos estudados foram: silagem sem inoculação de $B$. subtilis (controle); silagem inoculada com $B$. subtilis na concentração de $5 \times 10^{4} \mathrm{UFC} / \mathrm{g}$ de forragem; silagem inoculada com $B$. subtilis na concentração de $1 \times 10^{5} \mathrm{UFC} / \mathrm{g}$ de forragem; silagem inoculada com $B$. subtilis na concentração de $5 \times 10^{5} \mathrm{UFC} / \mathrm{g}$ de forragem. Após a inoculação, amostragens foram realizadas para caracterização da planta de milho (Tabela 1).

Tabela 1. Caracterização das plantas de milho antes da ensilagem

\begin{tabular}{ccccc}
\hline $\mathrm{MS}(\mathrm{g} / \mathrm{kg})$ & $\mathrm{pH}$ & $\mathrm{NH}_{3} / \mathrm{NT}$ & Leveduras & Fungos filamentosos \\
\hline 377,8 & 5,98 & 2,12 & 7,23 & 5,63 \\
\hline
\end{tabular}

$\overline{\mathrm{MS}}=$ matéria seca; $\mathrm{pH}=$ potencial hidrogeniônico; $\mathrm{NH}_{3} / \mathrm{NT}=$ nitrogênio amoniacal em relação ao nitrogênio total. Leveduras e fungos filamentosos em $\mathrm{Log} \mathrm{UFC} / \mathrm{g}$ de forragem.

Baldes plásticos, com capacidade de 7L, foram utilizados como silos experimentais, nos quais havia $0,5 \mathrm{~kg}$ de areia no fundo, separados da forragem por uma tela fina de plástico com malha, adequada para evitar o contato entre areia e silagem, para quantificação de efluentes. Os baldes foram fechados com tampa plástica, lacrados com fita adesiva e armazenados em temperatura ambiente. Decorridos 60 dias, os silos foram abertos e descartou-se 0 material deteriorado. $\mathrm{O}$ restante foi homogeneizado e acondicionado em baldes plásticos para determinação da estabilidade aeróbia.

Conceitualmente, a quebra da estabilidade aeróbia foi definida como o tempo necessário para que a silagem ultrapassasse a temperatura ambiente em $2^{\circ} \mathrm{C}$ (KUNG JUNIOR et al., 2003), entretanto, a avaliação dos valores de $\mathrm{pH}$, bem como a ocorrência de microorganismos deterioradores, após abertura dos silos também foram utilizados como critério para definir a quebra da estabilidade. A determinação das perdas de matéria seca (MS) por gás e efluente seguiu a metodologia descrita por Jobim et al. (2007).

Os baldes foram colocados em uma sala fechada, em temperatura ambiente, por 12 dias. A temperatura das silagens foi registrada, a cada meia hora, por um data logger, colocado no centro da massa, e a temperatura ambiente foi medida por data loggers distribuídos próximos aos recipientes. Segundo Jobim et al. (2007), a condução do ensaio de estabilidade aeróbia, em temperatura ambiente, apresenta alta acurácia na estimativa da velocidade de deterioração da silagem em situação de campo.

A determinação dos valores de $\mathrm{pH}$ e teores de $\mathrm{N}$ amoniacal, em relação ao $\mathrm{N}$ total $\left(\mathrm{NH}_{3} / \mathrm{NT}\right)$, foi realizada conforme metodologia descrita por Silva \& Queiroz (2002). O teor de MS foi calculado após secagem da amostra, em estufa de ventilação, forçada a $55^{\circ} \mathrm{C}$, durante 72 horas. Os teores de ácido lático foram determinados por espectrofotômetro colorimétrico (SILVA \& QUEIROZ, 2002), enquanto a determinação dos teores de ácido acético 
foi realizada por cromatografia gasosa (WILSON, 1971).

Durante o período de exposição aeróbia $(0 ; 4 ; 8$ e 12 dias), avaliações dos valores de $\mathrm{pH}$ e contagens de leveduras e fungos filamentosos foram realizadas $\mathrm{Na}$ contagem de leveduras e fungos filamentosos, utilizaram-se $25 \mathrm{~g}$ de silagem com base na matéria natural, às quais foram adicionados $225 \mathrm{~mL}$ de solução peptonada $0,1 \% \quad(0,1 \mathrm{~g} \quad$ de peptona por litro de água destilada). Após agitação, foi retirado $1 \mathrm{~mL}$ da diluição para as posteriores diluições de $10^{-2}$ a $10^{-5} \mathrm{e}$, a partir destas, realizaramse as semeaduras de $0,1 \mathrm{~mL}$ em placas de Petri, que continha o meio ágar batata, acidificado (Difco), incubadas em aerobiose a $28^{\circ} \mathrm{C}$. Na contagem das colônias de leveduras, as placas foram mantidas incubadas por 48 horas, enquanto a contagem de fungos filamentosos ocorreu nas mesmas, porém, 120 horas após o momento inicial da incubação (JOBIM et al., 1999). Na caracterização da planta de milho ensilada, quanto ao desenvolvimento de microorganismos, seguiu os mesmos procedimentos.

Utilizou-se o delineamento inteiramente casualizado, em esquema de parcelas subdivididas, em que as silagens constituíram as parcelas e os tempos de exposição aeróbia as subparcelas, com quatro repetições. Os dados obtidos foram submetidos à análise de variância por meio do software SISVAR ${ }^{\circledR}$ (FERREIRA, 2008), e aplicou-se a análise de regressão a $5 \%$ de significância, com posterior ajuste de equações.

\section{RESULTADOS E DISCUSSÃO}

A inoculação da forragem com diferentes doses de $B$. subtilis não promoveu alteração sobre as perdas por gases e efluentes, nem no teor de MS, nos valores de $\mathrm{pH}$, nas concentrações de $\mathrm{NH}_{3} / \mathrm{NT}$, ácido acético e lático, e na ocorrência de fungos filamentosos nas silagens de milho (Tabela 2).

Tabela 2. Média do teor de matéria seca (MS), características químicas, ocorrência microbiológica e perdas fermentativas de silagem de milho, inoculada com Bacillus subtilis aos 60 dias, após a ensilagem

\begin{tabular}{|c|c|c|c|c|c|c|}
\hline Item & Controle & $5 \times 10^{4}$ & $1 \times 10^{5}$ & $5 \times 10^{5}$ & $\mathrm{P}$ valor & $\mathrm{CV}(\%)$ \\
\hline MS (g/kg) & 374,9 & 367,1 & 354,9 & 365,6 & 0,1675 & 3,19 \\
\hline $\mathrm{pH}$ & 3,71 & 3,75 & 3,76 & 3,73 & 0,4262 & 1,88 \\
\hline $\mathrm{NH}_{3} / \mathrm{NT}(\mathrm{g} / \mathrm{kg})^{1}$ & 52,7 & 62,6 & 64,2 & 55,6 & 0,4675 & 19,60 \\
\hline Ácido acético (g/kg de MS) & 9,4 & 11,8 & 10,6 & 9,9 & 0,1894 & 15,03 \\
\hline Ácido lático (g/kg de MS) & 40,7 & 33,2 & 35,2 & 31,5 & 0,4209 & 19,47 \\
\hline Fungos filamentosos $^{2}$ & 4,90 & 5,14 & 4,54 & 4,47 & 0,7733 & 21,77 \\
\hline Perdas por gases $(\mathrm{g} / \mathrm{kg})$ & 28,9 & 22,7 & 27,4 & 27,6 & 0,0698 & 22,12 \\
\hline Perdas por efluente $(\mathrm{g} / \mathrm{kg} \text { de } \mathrm{MV})^{3}$ & 5,52 & 4,86 & 5,45 & 4,19 & 0,3770 & 23,27 \\
\hline
\end{tabular}


Os valores médios de $\mathrm{pH}$, as concentrações de $\mathrm{NH}_{3} / \mathrm{NT}$, de ácido lático e acético das silagens se enquadram na faixa que representa adequado processo fermentativo em silagem de milho, segundo Kung Junior \& Shaver (2001). Embora as perdas de MS por gases e efluente não tenham sido alteradas devido à inoculação da forragem com doses de B. subtilis, os valores aqui observados podem ser considerados baixos, o que está associado ao teor de MS adequado da forragem na ensilagem (Tabela 1). Ao estudarem a aplicação de aditivos biológicos em silagens de milho, Phillip \& Fellner (1992) relataram perdas de MS da ordem de 27,7 e 41,8g/kg na silagem controle e inoculada com $B$. subtilis $\left(1,5 \times 10^{5} \mathrm{UFC} / \mathrm{g}\right.$ de forragem $)$, respectivamente.

A ocorrência de leveduras no momento da abertura dos silos diminuiu linearmente $(\mathrm{P}=0,0286)$ nas silagens de milho, inoculadas com maiores doses de B. subtilis (Figura 1), o que pode ser justificado pela produção de compostos antifúngicos por essa bactéria (TODOVORA \& KOZHUHAROVA, 2009). Como se observou, não houve diferença quanto à concentração de ácido acético, que é o ácido orgânico, principal responsável pelo controle de microorganismos deterioradores (DANNER et al., 2003; KLEINSCHMIT \& KUNG JUNIOR, 2006).

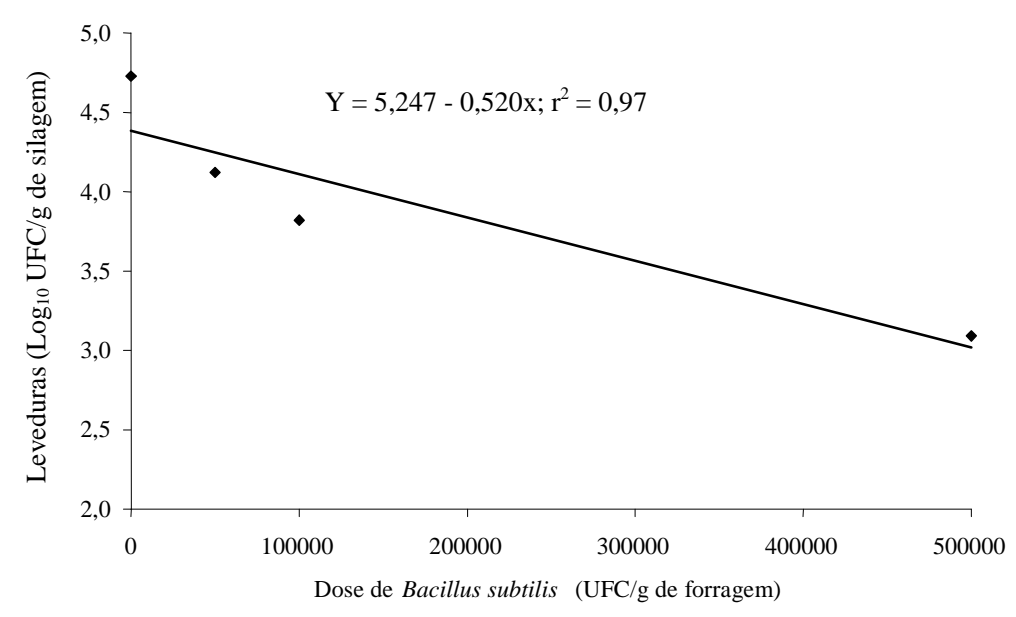

Figura 1. Ocorrência de leveduras nas silagens no momento da abertura dos silos, em razão das diferentes doses de Bacillus subtilis aplicadas na ensilagem

$\mathrm{Na}$ silagem controle, foi observado 4,72 $\log _{10}$ UFC de levedura/g de silagem, enquanto na silagem inoculada com $B$. subtilis na concentração de $5 \times 10^{5} \mathrm{UFC} / \mathrm{g}$ de forragem verificou-se a ocorrência de $3,16 \log _{10}$ UFC de levedura/g de silagem. A maioria dos antibióticos produzidos por B. subtilis são peptídeos, e, estes são ativos contra bactérias gram-positivas. No entanto, essa espécie também produz agentes eficazes contra o desenvolvimento de leveduras e fungos, como bacilomicina, micobacilina e fungistatina (TABBENE et al., 2009).

A ocorrência de leveduras, durante o período de exposição aeróbia, apresentou comportamento quadrático em resposta às doses de B. subtilis $(\mathrm{P}<0,001)$. As maiores doses empregadas implicaram no decréscimo da população de leveduras 
(Figura 2), o que é positivo, pois esse grupo de microorganismos é o principal responsável pela deterioração das silagens após abertura (ASHBELL et al., 2002; WOOLFORD, 1990).

Ao se considerar a média de todos os tratamentos quanto ao desenvolvimento da população de leveduras em silagens de milho após a abertura dos silos, notou-se aumento linear $(\mathrm{P}<0,001)$ dos microorganismos. A população de leveduras no momento da abertura foi $4,44 \log _{10} \mathrm{UFC} / \mathrm{g}$ de silagem, enquanto após 12 dias de exposição aeróbia o valor encontrado foi $9,53 \log _{10} \mathrm{UFC} / \mathrm{g}$ de silagem (Figura 3).

Borreani et al. (2002) verificaram que contagem de leveduras acima de $100.000 \mathrm{UFC} / \mathrm{g}$ de forragem $\left(5 \log _{10} \mathrm{UFC} / \mathrm{g}\right)$ resultaram em baixa estabilidade de silagens de milho (abaixo de 72 horas).

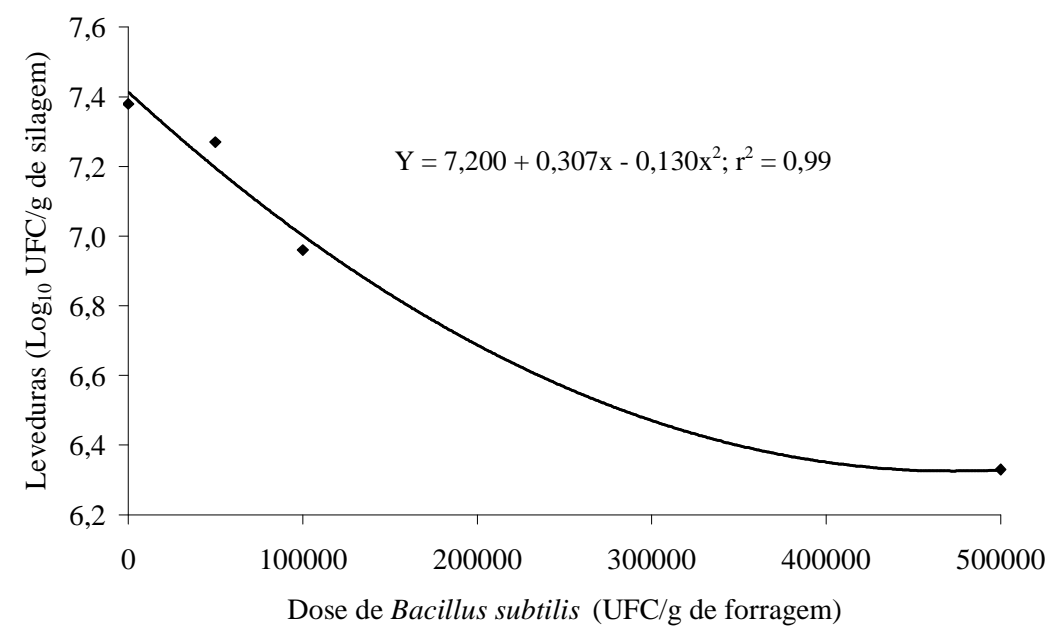

Figura 2. Ocorrência de leveduras em silagens de milho, inoculadas com doses de Bacillus subtilis, durante o período de exposição aeróbia

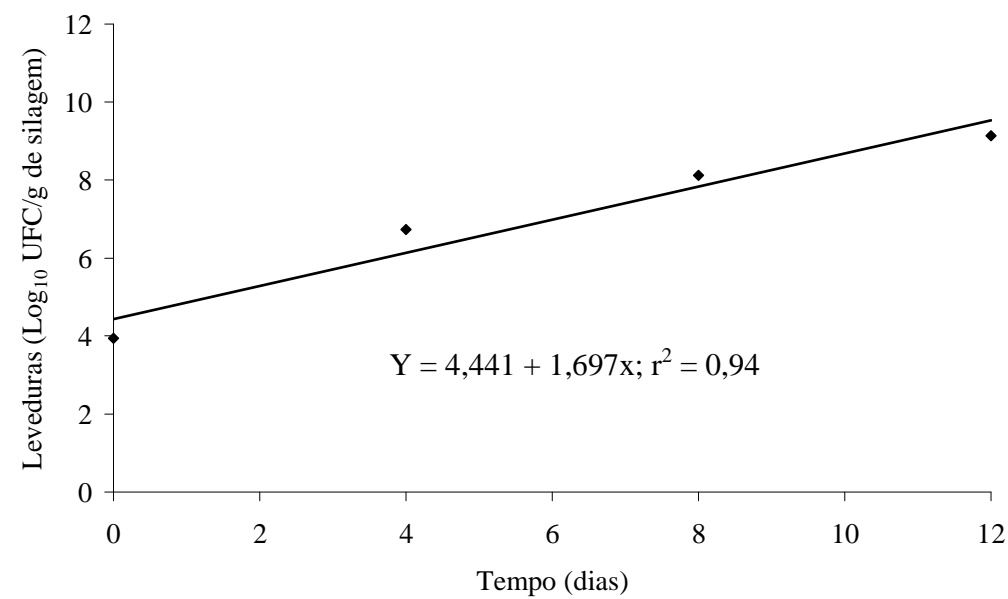

Figura 3. Desenvolvimento de leveduras, durante o período de exposição aeróbia, ao se considerar a média de todos os tratamentos 
O fato da população de leveduras aumentar, ao longo do período em aerobiose pode implicar baixo desempenho animal, pois, nessa fase, há intensa deterioração das silagens, principalmente, aquelas ricas em nutrientes e ácido lático. Kung Jr (2010) descreve que a ingestão de silagens é reduzida, quando a contagem de leveduras ultrapassa $10^{6} \mathrm{UFC} / g$ de forragem, embora as causas exatas ainda não sejam compreendidas.

Quanto à ocorrência de fungos filamentosos, houve efeito de tempo $(\mathrm{P}<0,001)$, assim como interação entre doses de $B$. subtilis e o tempo de exposição aeróbia $(\mathrm{P}=0,0430)$. Observou-se comportamento quadrático em todas as silagens, ao longo dos 12 dias de avaliação (Figura 4).

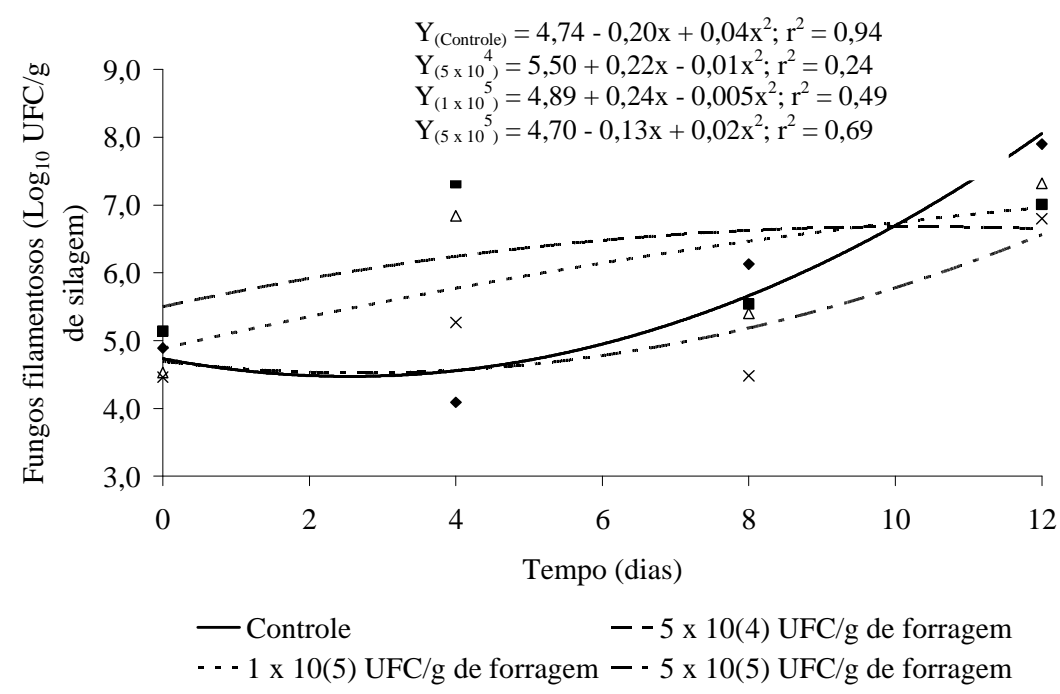

Figura 4. Ocorrência de fungos filamentosos em silagens de milho, inoculadas com Bacillus subtilis, durante o período de exposição aeróbia

No momento da abertura dos silos (dia 0 ), verificou-se que a contagem de fungos filamentosos nas silagens controle e inoculadas com B. subtilis nas concentrações de $5 \times 10^{4} ; 1 \times 10^{5}$ e $5 \times 10^{5} \mathrm{UFC} / \mathrm{g}$ de forragem foi de 4,74 ; 5,$50 ; 4,89$ e $4,70 \log _{10} \mathrm{UFC} / \mathrm{g}$ de silagem. Após 12 dias em exposição aeróbia, as mesmas silagens apresentaram 8,06; 6,$65 ; 6,96$ e 6,57UFC/g de silagem, respectivamente.

Como esperado, a contagem de fungos filamentosos aumentou durante $\mathrm{O}$ período em que as silagens ficaram expostas ao oxigênio (Figura 4), independente da dose de $B$. subtilis empregada na ensilagem, o que está correlacionado negativamente com a estabilidade aeróbia, conforme elucidado por Nishino et al. (2003). Como reportado na literatura, no decorrer dos dias em aerobiose é esperado que a temperatura das silagens aumente (Figura 5), em virtude do consumo de nutrientes por parte dos microorganismos oportunistas e indesejáveis, o que resulta em deterioração aeróbia da silagem. De acordo com Woolford (1990), tal aumento é causado principalmente pela atuação de leveduras e bactérias. Hill \& Leaver (2002) complementam que há aumento na temperatura das silagens, em virtude do balanço entre a taxa de 
Rev. Bras. Saúde Prod. Anim., Salvador, v.13, n.4, p.1009-1019 out./dez., 2012 http://www.rbspa.ufba.br ISSN 15199940

calor produzida pela atividade microbiana e as perdas de calor, o que está diretamente relacionado à oxidação da MS, que provoca perdas na forma de dióxido de carbono.
Nesse contexto, verificou-se comportamento quadrático $(\mathrm{P}<0,001) \mathrm{da}$ aplicação de doses de $B$. subtilis sobre a estabilidade aeróbia das silagens de milho (Figura 6).

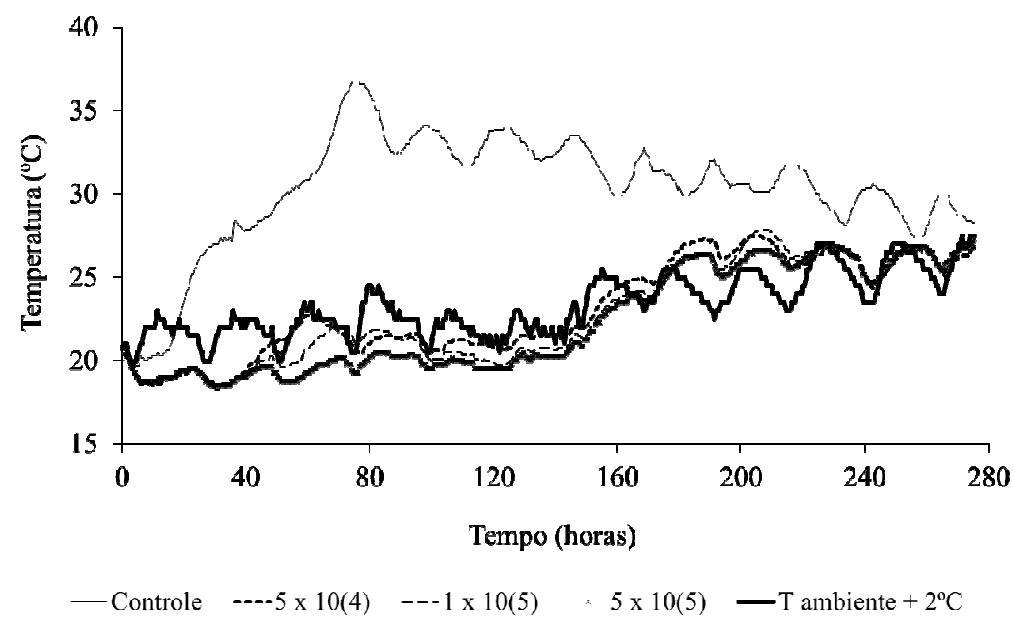

Figura 5. Temperatura das silagens durante o período de exposição aeróbia em função da inoculação com Bacillus subtilis

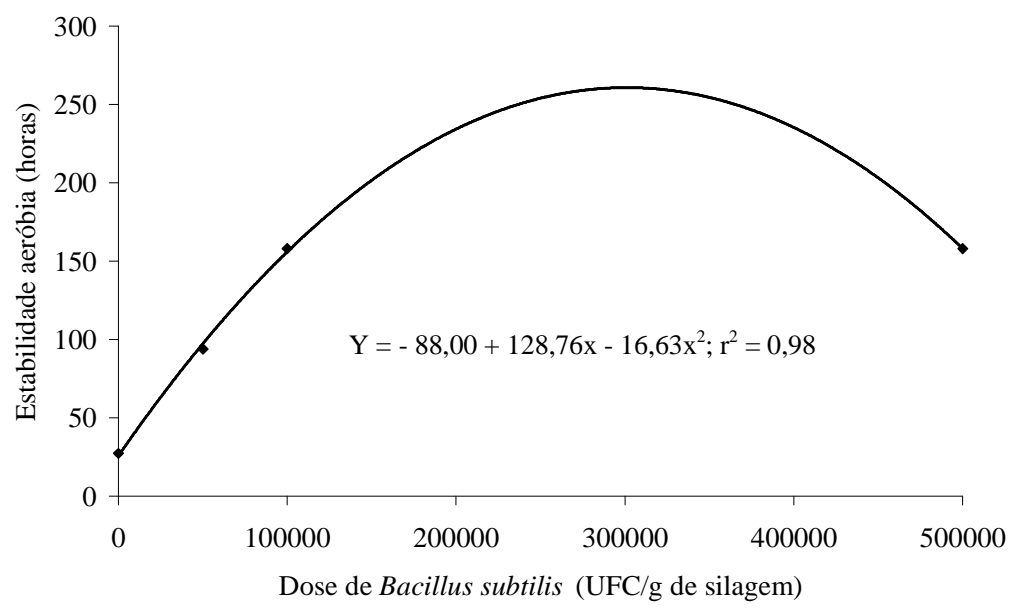

Figura 6. Estabilidade aeróbia de silagens de milho inoculadas com diferentes doses de Bacillus subtilis

Conforme a derivação da equação de regressão, observou-se que a silagem controle apresentou 24,12 horas de estabilidade aeróbia, enquanto as silagens inoculadas com $B$. subtilis nas concentrações de $1 \times 10^{5}$ e $5 \times 10^{5} \mathrm{UFC} / \mathrm{g}$ de forragem elevaram à 148,60 e 160,94 horas a quebra da estabilidade, respectivamente. Phillip \& Fellner (1992) verificaram que a aplicação de $B$. subtilis em silagem de milho na concentração de $1,5 \times 10^{5} \mathrm{UFC} / \mathrm{g}$ de forragem diminuiu a temperatura máxima da silagem em quase $6^{\circ} \mathrm{C}$, quando comparada à silagem 
controle $\left(32^{\circ} \mathrm{C}\right)$, o que implica maior estabilidade após abertura dos silos.

Quanto ao outro indicativo de deterioração aeróbia, os valores de $\mathrm{pH}$ das silagens, durante a exposição aeróbia foram alterados pelas doses de
B. subtilis $(\mathrm{P}=0,0008)$, pelo tempo de exposição aeróbia $(\mathrm{P}<0,001)$ e interação entre esses fatores $(\mathrm{P}=0,0011)$. Todas as silagens apresentaram comportamento quadrático quanto ao valor do $\mathrm{pH}$ ao longo dos dias (Figura 7).

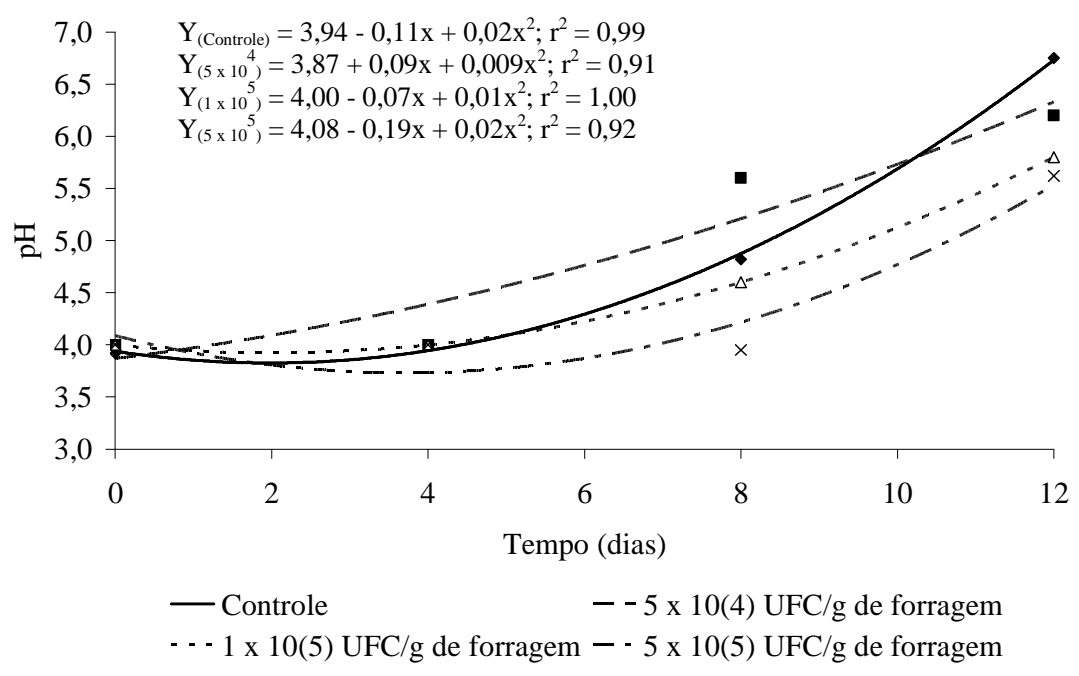

Figura 7. Valores de $\mathrm{pH}$ das silagens de milho inoculadas com Bacillus subtilis durante exposição aeróbia

De maneira geral, verificou-se que as silagens apresentaram $\mathrm{pH}$ adequado até 4 dias em exposição ao oxigênio, isto é, dentro da faixa de $\mathrm{pH}$ considerada ideal $(3,8$ a 4,2$)$ para um adequado processo fermentativo em silagem de milho (KUNG JR \& SHAVER, 2001). Contudo, vale ressaltar que não é adequado manter o painel do silo exposto ao oxigênio durante esse tempo, visto que, mesmo sem alteração do $\mathrm{pH}$, a produção de micotoxinas por fungos pode ser elevada (DRIEHUIS, 2011), o que pode comprometer o estado sanitário dos animais que consomem esta silagem.

Posteriormente, os valores de $\mathrm{pH}$ aumentaram, de modo a atingirem o pico após 12 dias de exposição aeróbia (Figura 7). Esses resultados estão associados à atuação das leveduras e fungos filamentosos, os quais utilizam ácido lático para se desenvolverem aerobicamente, de modo a elevar o $\mathrm{pH}$ da silagem e potencializar o crescimento de outros microorganismos indesejáveis, quando o $\mathrm{pH}$ está acima de 4,5 (REIS et al., 2008; MUCK, 2010).

Embora tenha sido reportado acréscimo nos valores de $\mathrm{pH}$ em todas as silagens, verificou-se que a silagem inoculada com B. subtilis na dose $5 \times 10^{5} \mathrm{UFC} / \mathrm{g}$ de forragem apresentou o menor valor após 12 (5,53) dias em aerobiose, se comparada à silagem controle $(6,73)$, o que está associado a menor ocorrência de micro-organismos deterioradores nessa silagem.

Em uma situação prática, esses resultados permitem inferir que as silagens que apresentaram maior 
estabilidade associada à menor ocorrência de leveduras e fungos filamentosos, mantém por maior tempo as características nutritivas e sanitárias observadas no momento da abertura. A inoculação de Bacillus subtilis na concentração de $5 \times 10^{5} \mathrm{UFC} / \mathrm{g}$ de forragem controla $\mathrm{o}$ crescimento dos micro-organismos deterioradores e melhora a estabilidade aeróbia da silagem de milho, de forma a manter os valores de $\mathrm{pH}$ mais estáveis na fase de pósabertura dos silos.

\section{REFERÊNCIAS}

ASHBELL, G.; WEINBERG, Z.G.; HEN, Y.; FILYA, I. The effects of temperature on the aerobic stability of wheat and corn silages. Journal of Industrial Microbiology and Biotechnology, v.28, p.261-263, 2002.

BORREANI, G.; TABACCO, E.; COLOMBARI, G. Influenza negli insilati nel deterioramento aerobico sulla qualità dei prodotti caseari.

L'Informatore Agrário, v.11, p.57-62, 2002.

DANNER, H.; HOLZER, M.; MAYRHUBER, E.; BRAUN, R. Acetic acid increases stability of silage under aerobic conditions. Applied and Environmental Microbiology, v.69, n.1, p.562-567, 2003.

DRIEHUIS, F. Occurrence of mycotoxins in silage. In:

INTERNATIONAL SYMPOSIUM ON FORAGE QUALITY AND CONSERVATION, 2, São Pedro. Proceedings... São Pedro, 2011. 20p.
FERREIRA, D.F. SISVAR: um programa para análises e ensino de estatística. Revista Científica Symposium, v.6, n.2, p.36-41, 2008.

HILL, J.; LEAVER, J.D. Changes in chemical composition and nutritive value of urea treated whole crop wheat during exposure to air. Animal Feed Science and Technology, v.102, p.181195, 2002.

JOBIM, C.C.; REIS, R.A.; SHOKENITURRINO, R.P.; ROSA, B.

Desenvolvimento de microrganismos durante a utilização de silagem de grãos úmidos de milho e de espigas de milho sem brácteas. Acta Scientiarum, v.21, p.671-676, 1999.

JOBIM, C.C.; NUSSIO, L.G.; REIS, R.A.; SCHMIDT, P. Avanços metodológicos na avaliação da qualidade da forragem conservada.

Revista Brasileira de Zootecnia, v.36, p.101-119, 2007. Supl. especial.

\section{KLEINSCHMIT, D.H.; KUNG}

JUNIOR, L. A meta-analysis of the effects of Lactobacillus buchneri on the fermentation and aerobic stability of corn and grass and small-grain silages.

Journal of Dairy Science, v.89, p.4005-4013, 2006.

KUNG JUNIOR, L.; SHAVER, R. Interpretation and use of silage fermentation analysis reports. Focus on Forage, v.3, p.1-5, 2001

KUNG JUNIOR, L.; TAYLOR, C.C.; LYNCH, M.P.; NEYLON, J.M. The effect of treating Alfafa with Lactobacillus buchneri 40788 on silage fermentation, aerobic stability, and nutritive value for lactating dairy cows. Journal Dairy Science, v.86, p.336343, 2003. 
KUNG JUNIOR, L. Aerobic stability of silage. In: ALFAFA \& FORAGE SYMPOSIUM AND CORN/CEREAL SILAGE CONFERENCE, Visalia. Proceedings... Visalia, 2010. 14p.

LANNA FILHO, R.; FERRO, H.M.; PINHO, R.S.C. Controle biológico mediado por Bacillus subtilis. Revista Trópica: Ciências Agrárias e Biológicas, v.4, n.2, p.12-20, 2010.

MUCK, R.E. Silage microbiology and its control through additives. Revista Brasileira de Zootecnia, v.39, p.183191, 2010. Supl. especial.

NISHINO, N.; YOSHIDA, M.; SHIOTA, H.; SAKAGUCHI, E. Accumulation of 1,2-propanediol and enhancement of aerobic stability in whole crop maize silage inoculated with Lactobacillus buchneri. Journal of Applied Microbiology, v.94, p.800807, 2003.

PHILLIP, L.E.; FELLNER, V. Effects of bacterial inoculation of high-moisture ear corn on its aerobic stability, digestion, and utilization for growth by beef steers. Journal of Animal Science, v.70, p.3178-3187, 1992.

REIS, R.A.; SCHOCKEN-ITURRINO, R.P.; ALMEIDA, E.O.; JANUSCKIEWICZ, E.R.; BERNARDES, T.F.; ROTH, A.P.T.P. Efeito de doses de Lactobacillus buchneri "CEPA NCIMB 40788" sobre as perdas nos períodos de fermentação e pós-abertura da silagem de grãos úmidos de milho. Ciência Animal Brasileira, v.9, p.923-934, 2008.

SILVA, D.J.; QUEIROZ, A.C. Análise de alimentos: métodos químicos e biológicos. 3ed. Viçosa: Universidade Federal de Viçosa, 2002. 235p.
TABENNE, O.; SLIMENE, I.B.; BOUABDALLAH, F.; MANGONI, M.L.; URDACI, M.C.; LIMAN, F. Production of anti-methicillin-resistant Staphylococcus activity from Bacillus subtilis sp. Strain B38 newly isolated from soil. Applied Biochemistry and Biotechnology, v.157, p.407-419, 2009.

TAYLOR, C.C.; RANJIT, N.J.; MILLS, J.A.; NEYLON, J.M.; KUNG JUNIOR, L. The effect of treating whole-plant barley with Lactobacillus buchneri 40788 on silage fermentation, aerobic stability, and nutritive value for dairy cows.

Journal Dairy Science, v.85, p.17931800, 2002

TODOVORA, S; KOZHUHAROVA, L. Characteristics and antimicrobial activity of Bacillus subtilis strains isolated from soil. Journal of Microbiology and Biotechnology, v.96, p.1151-1161, 2009.

WILSON, R.K.A. A rapid accurate method for messureng volatile fatty acids and lactic acid in silage. Dublin: Agricultural Institute, Dunsinea Research Centre, 1971.

WOOLFORD, M.K. The detrimental effects of air on silage. Journal of Applied Bacteriology, v.68, p.101-116. 1990.

ZEOULA, L.M.; BELEZE, J.R.F.; CECATO, U.; JOBIM, C.C.; GERON, L.J.V.; PRADO, O.P.P.; FALCÃO, A.J.S. Avaliação de cinco híbridos de milho (Zea mays L.) em diferentes estádios de maturação. Digestibilidade da matéria seca, matéria orgânica e fibra em detergente neutro da porção vegetativa e planta inteira. Revista Brasileira de Zootecnia, v.32, p.567-575, 2003.

Data de recebimento: 01/11/2011

Data de aprovação: 27/11/2012 